\title{
Open Fracture of Carpal Bone
}

National Cancer Institute

\section{Source}

National Cancer Institute. Open Fracture of Carpal Bone. NCI Thesaurus. Code C35231.

A traumatic break in one or more of the carpal bones that involves a break in the adjacent skin. 